\title{
Characterization of the P13 Membrane Protein of Borrelia burgdorferi by Mass Spectrometry
}

\author{
Carol L. Nilsson \\ Institute of Medical Biochemistry, Göteborg University, Göteborg, Sweden
}

Helen J. Cooper, Kristina Håkansson, and Alan G. Marshall
Ion Cyclotron Resonance Program, National High Magnetic Field Laboratory, Tallahassee, Florida, USA

Yngve Östberg, Marija Lavrinovicha, and Sven Bergström

Department of Molecular Biology, Umeå University, Umeå, Sweden

Borrelia burgdorferi sensu lato is a tick-borne pathogen that causes Lyme disease. The characterization of membrane proteins from this and other pathogens may yield a better understanding of the mechanisms of infection and information useful for vaccine design. Characterization of the highly hydrophobic Borrelia outer membrane component P13 from a mutant $\left(\mathrm{OspA}^{-} \mathrm{OspB}^{-} \mathrm{OspC}^{-}\right.$and $\left.\mathrm{OspD}^{-}\right)$strain was undertaken by use of a combination of mass spectrometric methods. In a previous investigation, an electrospray ionization (ESI) mass spectrum of the intact protein provided an average molecular weight that was $20 \mathrm{Da}$ lower than the predicted molecular weight. The mass deviation could be explained by a modification of the N-terminus of the protein such as pyroglutamylation $(-17 \mathrm{Da})$ in combination with the experimental error of measurement, however more information was required. New structural information for this membrane protein was provided by peptide mapping with matrix-assisted laser desorption/ionization time-of-flight mass spectrometry (MALDI TOF MS) and sequencing with ESI-quadrupole-TOF tandem MS. ESI Fourier transform ion cyclotron resonance (FT-ICR) MS at 9.4 tesla revealed that the Borrelia membrane protein is not only pyroglutamylated, but also contains an amino acid substitution near the N-terminus. (J Am Soc Mass Spectrom 2002, 13, 295-299) (C) 2002 American Society for Mass Spectrometry

B orrelia burgdorferi is a tick-borne pathogen that causes Lyme disease. The infection results in a wide range of clinical manifestations that may affect the skin, joints, heart, and nervous system [1]. Several investigations indicate that the borrelial cell envelope differs substantially from that of other Gramnegative bacteria [2-4]. B. burgdorferi cells contain an extraordinary abundance of lipoproteins, but the density of transmembrane spanning proteins in the outer membrane is low compared to other gram-negative bacteria [5]. The characterization of membrane proteins from this and other pathogens may yield a better understanding of the mechanisms of infection and information useful for vaccine design.

Mass spectrometry is a valuable technique for protein structural analysis. Peptide mapping [6-9] by MALDI-TOF MS can rapidly identify known proteins and their post-translational modifications. Peptide mapping may provide sufficient data alone, but tandem

Published online January 25, 2002

Address reprint requests to Dr. C. L. Nilsson, Institute of Medical Biochemistry, Göteborg University, Box 440, SE-405 Göteborg, Sweden. E-mail: carol.nilsson@medkem.gu.se mass spectrometry can be employed to obtain de novo amino acid sequences and confirm the nature of peptide post-translational modifications [10, 11]. High resolution, high mass accuracy techniques can improve the rate of success of identification of proteins for which the gene sequence is known, as well as post-translational modifications. The highest performance mass analyzer is the FT-ICR mass spectrometer [12]. Recent developments have demonstrated that analyses of biological materials can be performed at a high level of sensitivity, when microelectrospray [13] is the ionization mode [14-16].

Characterization of the highly hydrophobic Borrelia outer membrane component $\mathrm{P} 13$ from the $\mathrm{OspA}^{-}$ $\mathrm{OspB}^{-} \mathrm{OspC}^{-}$and $\mathrm{OspD}^{-}$mutant strain [17] was undertaken through a combination of mass spectrometric methods. In an earlier investigation [18], an electrospray ionization (ESI) mass spectrum of the intact protein provided an average molecular weight that was 20 Da lower than the predicted molecular weight. The mass deviation could be explained by a modification of the N-terminus of the protein such as pyroglutamylation $(-17 \mathrm{Da})$ in combination with the experimental error of measurement; however more information was 
required. Edman sequencing of the N-terminus failed, increasing the suspicion that the terminus was blocked. Because the P13 protein is immunogenic and a putative vaccine component, extensive characterization was desirable.

\section{Methods}

\section{Sample Preparation}

Approximately $0.1 \mathrm{mg}$ of $\mathrm{P} 13$ protein purified as previously described [18] was dissolved in SDS-PAGE sample buffer and electrophoresed in a 15\% SDS-PAGE gel (Novex). The gel was stained with GelCode Blue Stain Reagent (Pierce, USA). The protein band was excised and destained by adding $85 \mu \mathrm{L} 25 \mathrm{mM} \mathrm{NH}_{4} \mathrm{HCO}_{3}$ in $50 \%$ $\mathrm{CH}_{3} \mathrm{CN}$ and vortexing for $30 \mathrm{~min}$, after which the supernatant was removed. This procedure was repeated twice. Gel pieces were dried for $40 \mathrm{~min}$ in a vacuum centrifuge (SpeedVac, Savant Inc. USA). Fifteen $\mu \mathrm{L}$ modified porcine trypsin (sequencing grade, Promega) in $25 \mathrm{mM}$ $\mathrm{NH}_{4} \mathrm{HCO}_{3}, \mathrm{pH} 8$, was added. The tubes were incubated for $16 \mathrm{~h}$ at $37^{\circ} \mathrm{C}$. Peptides were extracted from the gel by

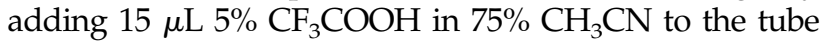
and vortexing for $30 \mathrm{~min}$. Extracted peptides were subsequently analyzed by mass spectrometry.

\section{MALDI-TOF-MS}

Samples were analyzed with a Micromass TofSpecE MALDI-TOF mass spectrometer (Micromass, Manchester, UK) equipped with a pulsed $337 \mathrm{~nm}$ nitrogen laser, a delayed extraction ion source and a reflectron. Onehalf $\mu \mathrm{L}$ sample was mixed with $0.5 \mu \mathrm{L}$ matrix solution (CHCA $10 \mathrm{mg} / \mathrm{mL}$ in acetonitrile: $\mathrm{H}_{2} \mathrm{O}, 1: 1$ ) directly on the cylindrically machined MALDI probe and allowed to dry at ambient conditions. Peptide spectra were acquired in reflectron mode at an accelerating voltage of $20 \mathrm{kV}$; 200 laser shots were summed. External calibration with angiotensin II and ACTH (18-39) was employed. This procedure typically results in mass accuracies of $200 \mathrm{ppm}$ or better. The mass accuracy can be improved to better than $100 \mathrm{ppm}$ if a second calibration with an autodigestion product of porcine trypsin (2211.105 Da) is performed. Resulting values for monoisotopic peaks were matched against the theoretical masses from tryptic digestion of the mature P13 protein according to the published sequence.

\section{ESI-Quadrupole-TOF-MS(/MS)}

Tryptic peptides were analyzed by nanoflow ESI-MS and tandem MS (MS/MS) in a QTof instrument (Micromass, Manchester, UK). Peptide samples were dissolved in $3 \mu \mathrm{L}$ acetonitrile: $\mathrm{H}_{2} \mathrm{O}(1: 1)$ containing $1 \%$ acetic acid and sprayed from gold-coated glass capillaries (Micromass). The collision gas was argon. Instrument calibration was performed by use of fragment ions from Glu-fibrinopeptide B and a fourth order polynomial fit. This proce- dure gives mass accuracies of 100 ppm or better. Both MALDI- and ESI-MS spectra were analyzed with the MassLynx (Manchester, UK) software.

\section{ESI-FTICR-MS}

A homebuilt, passively shielded, 9.4 tesla FT-ICR mass spectrometer [19] equipped with microelectrospray ionization [13] was used for accurate mass determination of the tryptic peptides. The peptides were infused at a flow rate of $500 \mathrm{~nL} / \mathrm{min}$ through an electrospray emitter consisting of a $50 \mu \mathrm{m}$ i.d. fused silica capillary, which had been mechanically ground to a uniform thin-walled tip [20]. The electrosprayed ions were transported into the mass spectrometer through a Chait-style atmosphere-to-vacuum interface [21] and externally accumulated [22] for $2 \mathrm{~s}$ in an octopole pretrap. After accumulation, the collected ions were transferred through multipole ion guides and captured by gated trapping in an open [23] cylindrical cell. The ions were subjected to chirp excitation (72 to $320 \mathrm{kHz}$ at 150 $\mathrm{Hz} / \mu \mathrm{s})$ and direct-mode broadband detection (1 Mword data points). Hanning apodization and one zero fill was applied prior to fast Fourier transform (FFT) followed by magnitude calculation. The experimental event sequence was controlled by a modular ICR data acquisition system (MIDAS) [24]. Internal frequency-to$\mathrm{m} / \mathrm{z}$ calibration [25] was performed with respect to two components $(\mathrm{m} / \mathrm{z} 922.00979$ and 1521.97146$)$ of an added \#G2421A electrospray tuning mix from Agilent Technologies (Wilmington, DE). The presented spectrum represents a sum of 30 time-domain transients.

\section{Results and Discussion}

\section{Peptide Mass Mapping of the P13 Protein by MALDI-TOF-MS}

All tryptic peptides except one, corresponding to the highly hydrophobic amino acid sequence 26-76, were detected and assigned (Table 1). The two autolytic peptides from trypsin were not visible in the MALDI spectrum, therefore the error of measurement was approximately $150 \mathrm{ppm}$. The peptide observed at $\mathrm{m} / \mathrm{z}$ 1711.9 corresponds to the unmodified N-terminal peptide (QANDSKNGAFGMSAGEK) of the published amino acid sequence, within the error of the MALDI measurement. This result is at odds with previous data, which suggested that the N-terminus is modified, however the peptide at $\mathrm{m} / \mathrm{z} 1696.0$ deviates by $+1 \mathrm{Da}$ from the pyroglutamylated form of the $\mathrm{N}$-terminal peptide.

\section{MS/MS of a Doubly Protonated Peptide at $\mathrm{m} / \mathrm{z}$ 848.4}

Tandem mass spectrometry was performed on a doubly protonated precursor ion observed at $\mathrm{m} / \mathrm{z} 848.4$ with the QTof instrument, corresponding to the singly protonated peptide at $m / z 1696.0$ in the MALDI-TOF spectrum 
Table 1. Summary of ions observed in MALDI-TOF-MS analysis of tryptic digest P13 protein from Borrelia burgderferi

\begin{tabular}{lccc}
\hline Assignment $^{\mathrm{a}}$ & $\mathrm{M}+\mathrm{H}^{+}$(calc.) & $\mathrm{M}+\mathrm{H}^{+}$(obs.) & Dev. (ppm) \\
\hline \hline$(18-25)$ & 952.54 & 952.66 & 126 \\
$(85-93)$ & 1094.54 & 1093.69 & 137 \\
$(84-937)$ & 1222.64 & 1222.80 & 131 \\
$(94-107)$ & 1404.77 & 1404.99 & 157 \\
$(94-107)$ Met-ox & 1420.77 & 1420.97 & 141 \\
$(94-107)$ 2Met-ox & 1436.76 & 1436.97 & 146 \\
??(1-17)pGlu & 1694.74 & 1695.99 & $\mathrm{~b}$ \\
$(1-17)$ & 1711.77 & 1711.88 & 64 \\
$108-123$ & 1899.00 & 1899.26 & 137 \\
$(77-93)$ & 1921.03 & 1921.20 & 88 \\
$(108-124)$ & 2027.10 & 2027.35 & 123 \\
\hline
\end{tabular}

${ }^{a}$ Assignments were made by comparing observed peptide masses with a theoretical digest of the mature P13 protein according to the published sequence.

${ }^{b}$ Out of mass accuracy range.

with a mass deviation of +1 Da compared to the pyroglutamylated form of the published N-terminal sequence. The MS/MS spectrum (Figure 1) gave the amino acid sequence (pQANDSKDGAFGMSAGEK), providing evidence that the peptide is pyroglutamylated and contains one amino acid substitution. The substitution of $\mathrm{D}$ for $\mathrm{N}$ leads to an increase in mass of 1 Da. No satisfactory MS/MS data was obtained for the peptide corresponding to protonated mass 1711.9 .

\section{ESI-FTICR-MS of the Tryptic Digest}

After finding the amino acid substitution N7D, we realized that the singly protonated peptide at $\mathrm{m} / \mathrm{z}$ 1711.9, as measured by MALDI-TOF- and ESI-qTOFMS, could match two possible forms of the protein $\mathrm{N}$-terminus within the range of experimental error of these instruments: the unmodified peptide QANDSKN GAFGMSAGEK (monoisotopic protonated mass 1711.7701), or the pyroglutamylated and methionine oxidized form pQANDSKDGAFGM ${ }^{*}$ SAGEK (monoisotopic protonated mass 1711.7226), which differ by the

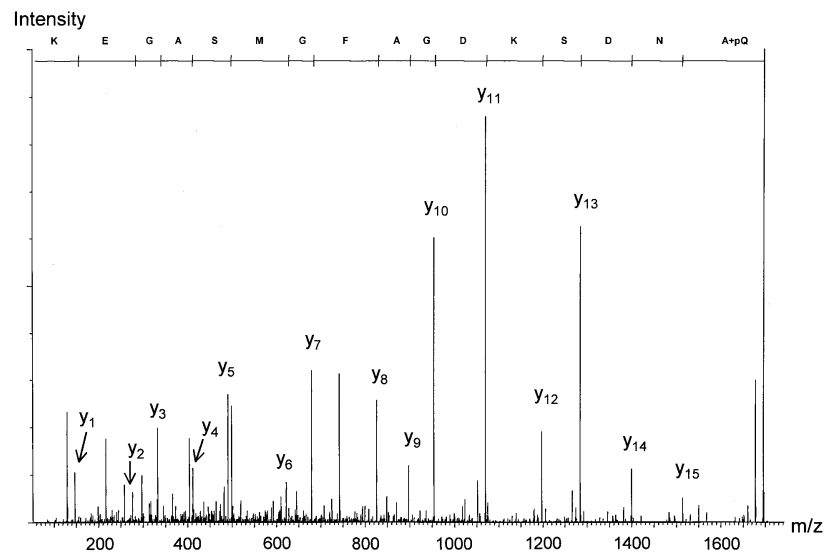

Figure 1. MS/MS spectrum of a doubly protonated peptide of $\mathrm{m} / \mathrm{z} 848.4$ in an ESI-qTOF mass spectrometer. The spectrum revealed pyroglutamylation of the N-terminus and the substitution of $\mathrm{D}$ for $\mathrm{N}$ at the seventh position. elemental composition $\mathrm{N}_{2} \mathrm{H}_{4}$ versus $\mathrm{O}_{2}$. Therefore, the digest was analyzed in the high performance 9.4 tesla FTICR instrument at the National High Magnetic Field Laboratory (NHMFL) in Tallahassee, Florida, fitted with a microelectrospray source. The spectrum is shown in Figure 2 and the results summarized in Table 2. The mass accuracy of the FT-ICR instrument unambiguously identified the $\mathrm{m} / \mathrm{z} 1711.9$ peptide as the methionine oxidized form of the pyroglutamylated $\mathrm{N}$ terminal peptide with the sequence pQANDSKDGAF GMSAGEK.

\section{Conclusion}

The results of this investigation serve to illustrate the relative strengths and limitations of three of the mass

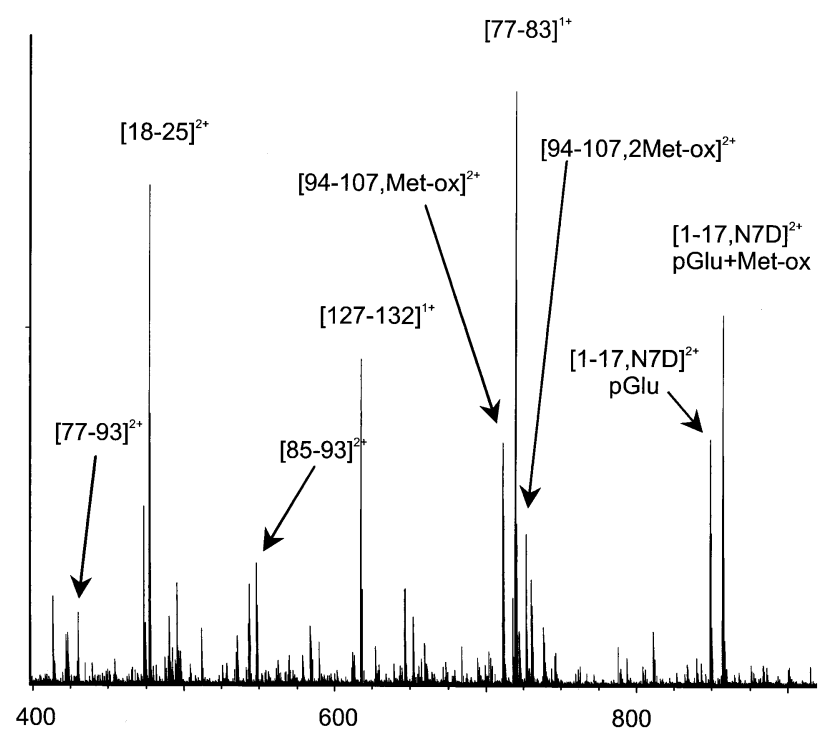

Figure 2. 9.4 tesla FTICR mass spectrum obtained by microelectrospray ionization of an unfractionated tryptic digest of the P13 membrane protein of a mutant strain of Borrelia burgdorferi. The achieved resolving power was approximately 35,000 and mass accuracy was better than $2 \mathrm{ppm}$. Peptide assignments are given in brackets. 
Table 2. Summary of N-terminal peptide ions from a tryptic digest of protein P13, assigned through MALDI- (M), ESI-qTOF- (Q), and FT-ICR-MS (F) data

\begin{tabular}{|c|c|c|c|}
\hline Peptide ion & $\mathrm{M}+\mathrm{H}^{+}$(calc.) & $\mathrm{M}+\mathrm{H}^{+}$(obs.) $)^{\mathrm{a}}$ & dev. (ppm) \\
\hline \multirow{3}{*}{$(1-17)$} & 1711.7710 & $1711.88 \quad \mathrm{M}$ & 64 \\
\hline & & $1711.74 \quad \mathrm{Q}$ & 18 \\
\hline & & $1711.7205 F$ & $30^{\mathrm{b}}$ \\
\hline \multirow[t]{3}{*}{ 1-17, N7D)pGlu+Met-ox } & 1711.7234 & $1711.88 \mathrm{M}$ & 92 \\
\hline & & $1711.74 \quad \mathrm{Q}$ & 96 \\
\hline & & $1711.7205 F$ & 1.7 \\
\hline \multirow[t]{3}{*}{ 1-17, N7D) pGlu } & 1695.7284 & $1695.99 \mathrm{M}$ & 154 \\
\hline & & $1695.75 \quad \mathrm{Q}$ & 13 \\
\hline & & $1695.7267 F$ & 1.0 \\
\hline
\end{tabular}

aNote that the observed masses obtained by MALDI- and ESI-qTOF MS can match more than one peptide within the range of their mass accuracy (150 ppm). With ESI-FTICR-MS analysis, at an accuracy of $2 \mathrm{ppm}$, this ambiguity was removed.

${ }^{\mathrm{b}}$ Out of mass accuracy range.

spectrometric techniques that are most widely employed in protein characterization. Peptide mapping by MALDI-TOF-MS is a rapid and sensitive technique, but incorrect assignments of peptide identities, based on molecular mass alone, may result if mass accuracy is low. Here, the relatively low mass accuracy (of the order of $150 \mathrm{ppm}$ ) of the MALDI-TOF data resulted in an incorrect assignment of the peptide of $\mathrm{m} / \mathrm{z} 1711.9$ to the unmodified N-terminal peptide of the published (and for this strain, incorrect) P13 protein sequence. The peptide of $\mathrm{m} / \mathrm{z} 1696.0$ revealed an incongruity in the actual protein and its published sequence, and stimulated further investigation.

Tandem mass spectrometry is an excellent tool to obtain sequence confirmation for tryptic peptides, often resulting in spectra from which the amino acid sequence can be read directly. An unambiguous MS/MS spectrum from a doubly protonated peptide of $\mathrm{m} / \mathrm{z} 848.4$, corresponding to the measured singly protonated peptide of $\mathrm{m} / \mathrm{z} 1696.0$ by MALDI-TOF-MS, demonstrated the cyclization of the N-terminal glutamine residue and the substitution of $\mathrm{D}$ for $\mathrm{N}$ in the seventh position. However, no conclusive MS/MS spectrum was obtained for the peptide corresponding to the ion of $\mathrm{m} / \mathrm{z} 1711.9$ observed by MALDI-TOF-MS. The molecular mass of this species could be assigned to two possible sequences within the mass accuracy limits of the MALDI-TOF and ESI-qTOF analyses (Table 2). However, the high mass accuracy $(<2 \mathrm{ppm})$ data provided by the 9.4 tesla ESI-FTICR instrument at the NHMFL confirmed that the Borrelia membrane protein was pyroglutamylated and contained a substitution of $\mathrm{D}$ for $\mathrm{N}$ at the seventh position, the result of a point mutation of adenine to guanine in the genetic material of this strain. The new structural information for this membrane protein was thus provided by several mass spectrometric techniques. Because the $\mathrm{N}$-terminus may be surface-exposed and accessible to the cellular and humoral immune systems, the information is highly relevant to vaccine design.

\section{Acknowledgments}

This work was presented as a poster at the 49th ASMS Conference on Mass Spectrometry and Allied Topics, Chicago, IL, 2001, and was supported by the Swedish Society for Medical Research, Medical Faculty of Göteborg University, Swedish Society for Clinical Chemistry, the Swedish Medical Research Council (grant No. 07922, SB and Nos. 14113, A0692, CLN), SSF (Infection\&Vaccinology), NSF (CHE-99-09502), NIH (GM-31683), Florida State University, the National High Magnetic Field Laboratory in Tallahassee, Florida, and the Swedish Foundation for International Cooperation in Research and Higher Education (STINT).

\section{References}

1. Steere, A. C. Lyme Disease. N. Engl. J. Med. 1989, 321, 586-596.

2. Cox, D. L.; Akins, D. R.; Bourell, K. W.; Lahdenne, P.; Norgard, M.; Radolf, J. D. Limited Surface Exposure of Borrelia burgdorferi Outer Surface Lipoproteins. Proc. Natl. Acad. Sci. U.S.A. 1996, 93, 7973-7978.

3. Takayama, K.; Rothenberg, R. J.; Barbour, A. G. Absence of Lipopolysaccharide in the Lyme Disease Spirochete, Borrelia burgdorferi. Infect. Immun. 1987, 55, 2311-2313.

4. Belisle, J. T.; Brandt, M. E.; Radolf, J. D.; Norgard, M. V. Fatty Acids of Treponema pallidum and Borrelia burgdorferi Lipoproteins. J. Bacteriol. 1994, 176, 2151-2157.

5. Radolf, J. D.; Goldberg, M. S.; Bourell, K.; Baker, S. I.; Jones, J. D.; Norgard, M. V. Characterization of Outer Membranes Isolated from Borrelia burgdorferithe Lyme Disease Spirochete. Infect. Immun. 1995, 63, 2154-2163.

6. Pappin, D. J. C.; Hojrup, P.; Bleasby, A. J. Rapid Identification of Proteins by Peptide-Mass Fingerprinting. Curr. Biol. 1993, 3, 327-332.

7. Mann, M.; Højrup, P.; Roepstorff, P. Use of Molecular Weight Information to Identify Proteins in Sequence Databases. Biol. Mass Spectrom. 1993, 22, 338-345.

8. James, P.; Quadroni, M.; Carafoli, E.; Gonnet, G. Protein Identification in DNA Databases by Peptide Mass Fingerprinting. Biochem. Biophys. Res. Commun. 1993, 195, 58-64.

9. Yates, J. R.; Speicher, S.; Griffin, P. R.; Hunkapiller, T. Peptide Mass Maps: A Highly Informative Approach to Protein Identification. Anal. Biochem. 1993, 214, 397-408.

10. Shevchenko, A.; Jensen, O. N.; Podtelejnikov, A. V.; Sagliocco, F.; Wilm, M.; Vorm, O.; Mortensen, P.; Shevchenko, A.; Boucherie, H.; Mann, M. Linking Genome and Proteome by Mass Spectrometry: Large-Scale Identification of Yeast Pro- 
teins from Two Dimensional Gels. Proc. Natl. Acad. Sci. U.S.A. 1996, 93, 14440-14445.

11. Jensen, O. N.; Wilm, M.; Shevchenko, A.; Mann, M. Peptide Sequencing of 2-DE Gel-Isolated Proteins by Nanoelectrospray Tandem Mass Spectrometry. Methods Mol. Biol. 1999112, 112, 571-588.

12. Marshall, A. G.; Hendrickson, C. L.; Jackson, G. S. Fourier Transform Ion Cyclotron Resonance Mass Spectrometr: A Primer. Mass. Spectrom. Rev. 1998, 17, 1-35.

13. Emmett, M. R.; Caprioli, R. M. Micro-Electrospray MS: UltraHigh Sensitivity Analysis of Peptides and Proteins. J. Am. Soc. Mass Spectrom. 1994, 5, 605-613.

14. Belov, M. E.; Gorshkov, M. V.; Udseth, H. R.; Anderson, G. A.; Smith, R. D. Zeptomole-Sensitivity Electrospray IonizationFourier Transform Ion Cyclotron Resonance Mass Spectrometry of Proteins. Anal. Chem. 2000, 72, 2271-2279.

15. Martin, S. E.; Shabanowitz, J.; Hunt, D. F.; Marto, J. A. Subfemtomole MS and MS/MS Peptide Sequence Analysis Using Nano-HPLC Micro-ESI Fourier Transform Ion Cyclotron Resonance Mass Spectrometry. Anal. Chem. 2000, 72, $4266-4274$.

16. Quenzer, T. L.; Emmett, M. R.; Hendrickson, C.; Kelly, P. H.; Marshall, A. G. High Sensitivity Fourier Transform Ion Cyclotron Resonance Mass Spectrometry for Biological Analysis with Nano-LC and Microelectrospray Ionization. Anal. Chem. 2000, 73, 1721-1725.

17. Sadziene, A.; Thomas D. D; Barbou, A. G. Borrelia burgdorferi Mutant Lacking Osp: Biological and Immunological Characterization. Infect. Immun. 1995, 63, 1573-1580.
18. Noppa, L.; Östberg, Y.; Lavrinovicha, M.; Bergström, S. P13, an Integral Membrane Protein of Borrelia burgdorferi is C-Terminally Processed and Contains Surface-Exposed Domains. Infect. Immun. 2001, 69, 3323-3334.

19. Senko, M. W.; Hendrickson, C. L.; Pasa-Tolic, L.; Marto, J. A.; White, F. M.; Guan, S.; Marshall, A. G. Electrospray ionization Fourier Transform Ion Cyclotron Resonance at 9.4 T. Rapid Commun. Mass Spectrom. 1996, 10, 1824-1828.

20. Quinn, J. P.; Emmett, M. R.;Marshall, A. G. A Device for Fabrication of Emitters for Low-Flow Electrospray Ionization. Proceedings of the 46th ASMS Conference on Mass Spectrometry and Allied Topics; Orlando, FL 1998 p 1388.

21. Chowdhury, S. K.; Katta, V.; Chait, B. T. An ElectrosprayIonization Mass Spectrometer with New Features. Rapid Commun. Mass Spectrom. 1990, 4, 81-87.

22. Senko, M. W.; Hendrickson, C. L.; Emmett, M. R.; Shi, S. D.-H.; Marshall, A. G. External Accumulation of Ions for Enhanced Electrospray Ionization Fourier Transform Ion Cyclotron Resonance Mass Spectrometry. J. Am. Soc. Mass Spectrom. 1997, 8, 970-976.

23. Beu, S. C.; Laude, D. A., Jr. Open Trapped Ion Cell Geometries for Fourier Transform Ion Cyclotron Resonance Mass Spectrometry. Int. J. Mass Spectrom. Ion Processes 1992, 112, 215-230.

24. Senko, M. W.; Canterbury, J. D.; Guan, S.; Marshall, A. G. A High-Performance Modular Data System for Fourier Transform Ion Cyclotron Resonance Mass Spectrometry. Rapid Commun. Mass Spectrom. 1996, 10, 1839-1844.

25. Ledford, E. B., Jr; Rempel, D. L.; Gross, M. L. Space Charge Effects in Fourier Transform Mass Spectrometry. Mass Calibration. Anal. Chem. 1984, 56, 2744-2748. 